\title{
Light within algal cultures; Implications from light intensities within a lens
}

\author{
Heinrich Bührer \\ Swiss Federal Institute for Environmental Science and Technology (EAWAG/ETH), \\ Ueberlandstr. 133, 8600 Dübendorf, Switzerland
}

Key words: Light, algae, culture, ray optics, flicker, refraction.

\begin{abstract}
Continuous, homogeneous lighting conditions are fiction. The form of the culture vessel, as well as the light source and the culture density, influence the light field within a culture. What actually happens is due to the alteration of light within an optical lens. This also applies to the usual exposition devices used for studying primary production. In the worst case, with a point source and without any precautions, as much as $10 \%$ of the lens (vessel) volume is shaded by optical effects, whereas light is concentrated along a focus within the lens. Stirring of algal cultures introduces time, so focusing is transformed into flickering. A solution is to immerse the vessel in a water bath of rectangular shape.
\end{abstract}

\section{Introduction}

Algal cultures are maintained in containers of different forms and qualities (Grima et al., 1999, Marquez et al., 1995, Tardos et al., 1993). Algae can be cultivated in Erlenmeyer flasks or in cylindrical vials. For mass cultivation, containers with various diameters from cylindrical vials to very long glass tubes (as plug-flow systems) are used (Soeder, 1975, Garcia-Camacho et al., 1999). At the upper end are large shallow ponds, e.g. of Kohlenstoffbiologische Forschungsstation (non-axenic) (Soeder, 1975). Parameters given in literature for cultivating conditions are usually the light intensity at the surface of the container, as well as the maximum extinction of the algae. Other characteristics provided are the chemical composition of the cultural medium (main component, buffering of $\mathrm{pH}$, etc.) (Uehlinger, U. 1980; Gavrieli, J. 1984).

The light conditions within the vial itself are generally neglected. E. A. Thomas tried to optimize light conditions using a mirror assembly ${ }^{1}$.

Light probes of the size and sensitivity for entering a cultivating vial are not available, but light can be calculated by means of geometrical (ray) optics. There

\footnotetext{
${ }^{1}$ Thomas, E. A.: Mirror Closet, dismantled 1999. personal comm. F. Schanz (2000).
} 
has been long-lasting discussions on what is going on in planktonic algae under changing light conditions (GAP 1998). Planktonic algae move in the water body, not only in horizontal but also in vertical directions. As light is less in deeper layers, plankton undergoes changing light conditions.

The highest changes are near the surface with slight wind and sunshine because the surface waves are focusing the picture of the sun to a depth of some decimeters. An apparent sun diameter of 0.6 degrees and a wave speed of $1 \mathrm{~m} / \mathrm{s}$ gives a light pulse of 3 milliseconds with a light intensity of some 100 times higher than the average. Some of the so-called "UV-effects" may be related to this phenomenon.

It is assumed that a cross-section of a vial is an appropriate reduced representation of the culture vessel. Two centered circles can represent such a cylindrical chemostat. A point source is used as light.

Common features of all cultivation vessels are:

1. Use of glass (or transparent/translucent plastic) with a different refractive index than water.

2. Filled with a transparent nutrient solution (water)

3. Light source

4. Gas exchange

The most inexpensive way is using an Erlenmeyer flask with a cotton stopper placed on a North-facing windowsill. The usual way is to culture flasks on a shaking device equipped with artificial light.

\section{Local variation by reflection (catoptrics)}

The first set-up (on a South-facing windowsill) is used as a pre-concentration step to isolate flagellates. If there is only a thin layer of water in the vessel, light is focused by reflection from the back walls onto a catacaustic line (Fig.1), that attracts positive phototactic flagellates. The geometry is a reflection of an elliptic curve, i.e. a circular cylinder that is tilted. The altitude of the sun defines the ratio of the elliptic axes.

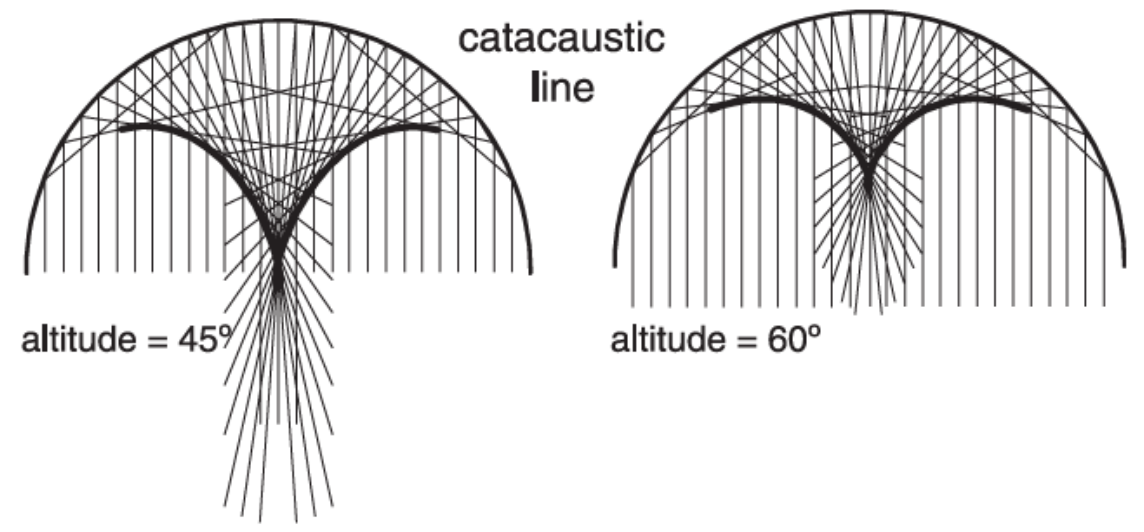

Figure 1. Catacaustic line within a shallow culture, caused by the reflections of sunlight at the back wall 


\section{Variation with time}

Most culture conditions are described as working with constant light. However, this is true only if the light source is operated with direct current. The normal electricity outlet in a laboratory has alternate current that causes some changes in light intensity. The emitted light of an incandescent lamp varies according to electrical energy consumed. At a heat radiator a smoothing is completed by the heat capacity of the Tungsten (W/Os) filament: 60Hz/110V (American standard) electric - lights flicker less than $50 \mathrm{~Hz} / 230 \mathrm{~V}$ (European standard): Intensity ${ }_{\min } /$ Intensity $_{\max }$, America: $<7 \%$. Europe: $<20 \%$ (power: $300 \mathrm{~W}$, black body, Stefan Bolzmann). ${ }^{2}$

$$
\begin{array}{ll}
\mathrm{R} & =\mathrm{L} \cdot \mathrm{k} / \mathrm{Q}: \quad \mathrm{R}=\text { Resistance, } \mathrm{L}=\text { length, } \mathrm{k}=\text { constant; } \\
\mathrm{Q}=\text { area of cross section }
\end{array}
$$

For fluorescent tubes, smoothing is correlated with the fluorescent properties of the tube coating ("phosphor"), which also changes the quality of the light. The primary radiation is the distinct emission bands of a low pressure Mercury arc with an intensive green and UV radiation $(254 \mathrm{~nm})$ that is transformed into visible light. Dimming increases the flickering. Intensive flickering can be produced by using an inappropriate combination of dimmer, ballast and tube. The easiest way to compensate the temporal light change is to use all 3 phases separately, each with it's own dimmer and lamp.

Another solution is higher frequencies: The QL-tubes of Philips (or Osram T8) are operated with some $40 \mathrm{kHz}$ (T8 $>20 \mathrm{kHz}$ ) in which flickering is low. Then, dimming becomes a problem.

\section{Variation with space (light within a culture)}

For a cylindrical shaped culture vessel, and with light coming from the sides, the following geometry is valid: in essence there is a glass cylinder, filled with culture medium either immersed in a water bath or just surrounded by air (avoiding the problem of inhibiting growth in the bath). As the glass and the water in the vessel form an optical lens, cultivation conditions for growing algae are within an optical lens.

As there are no light sensors available, which would be appropriate to measure the point light intensities in distances of millimeters, the light field can be calculated using, e.g., MS-Visual Basic. A cross-section of the vessel was partitioned into 1440 equal parts with 48 sectors and 30 circles (cf. Fig. 3).

The mathematical problem is not comparable with the problem of focusing the optical rays of an object into a sharp picture (which is a problem in designing camera

\footnotetext{
2 Assuming the same geometry of the filament. American filaments are straight rods whereas the correspondent European halogen burner filaments are coiled, which enhances the surface and diminishes the heat capacity, and leads to an even higher European flickering. The European construction type also lowers the temperature of the contacts.
} 
or binocular lenses), but of calculating the light intensity within a lens of the type of the old fashioned shoemaker ball (a glass bulb filled with water that focused the candle light on the working area). The underlying formulas use refraction law ${ }^{3 a}$, as well as Fresnel's ${ }^{3 b}$ laws (CRC 1998), that considers different polarizations of light and Lambert Beer's law of extinction. For simplifying the problem, light scattering and secondary reflections were neglected. The intensities were calculated by taking a light $1 \mu \mathrm{m}$ apart and comparing it with the first result.

The remaining problem is the focusing line where light reaches infinity. The light intensities are multiples of the incident light, but the exact amount depends mainly on the geometry of the light source. As point light is only a physical fictional entity, calculation was stopped at 20. Actually, these intensities can be much higher. This shortcut also eased the design of the figures where the surface of light intensities is thought to be impervious (a high-rising wall would conceal every thing behind it).

\section{Results}

The geometry of EAWAG's continuous culture vessels was used (Hirsbrunner 1971, Uehlinger 1980, Gavrieli 1984; the same equipment was used by H. Bachmann until 1998) consisting of an upright cylinder, $12 \mathrm{~cm}$ diameter and glass wall $3 \mathrm{~mm}$ thick. These vessels are surrounded by air and contain water.

With parallel light, i.e. a point light source at a sufficient distance and no algae the center of the cylinder receives 1.246 of the light intensity as would be reported for inscending light (Fig. 2). But neglected are two shaded areas without any light in
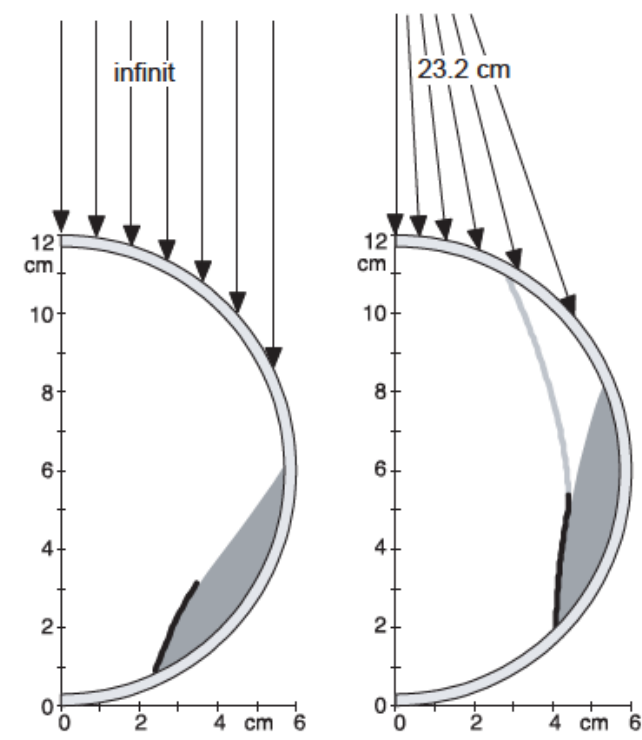

Figure 2. Light focussing: Left: Light source in infinity, right: point source at $23.2 \mathrm{~cm}$

${ }^{3}$ W. Snell van Royen 1581-1626; Augustin Jean Fresnel 1788-1827. 


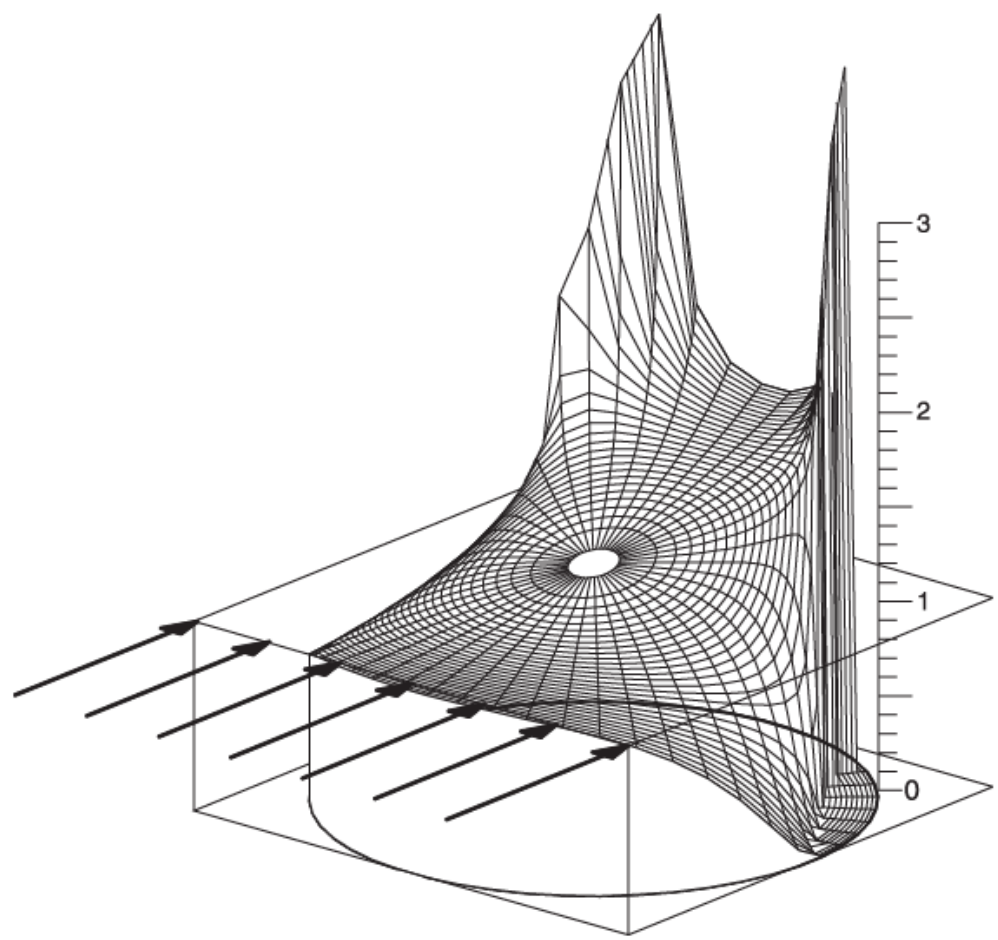

Figure 3. Light intensities in clear water: Light distance infinite, point source, and no algae; Light in center: 1.246 , average: 1.05

the back "corners" in which light is focused as a line starting at the back wall and ending within the vessel. The focusing line generated by a light source within $23.2 \mathrm{~cm}$ stretches throughout the vessel.

Figure 3 is drawn in parallel projection, which gives a somewhat strange appearance but allows measuring within the figure. On the backside is much more light because of the focusing effect. As glass has a higher refraction index than water, the additional light that would pass outside of the culture medium is focused also into the water and results in an additional $5 \%$ of average light. With addition of algae, the light field is modified along the light paths according to Lambert's law. A minimal intensity is noticed at the back wall where the paths are the longest (Fig. 4). The light intensities at the front and the back are equal for chlorophyll contents of about $10 \mathrm{mg} \mathrm{Chl} \mathrm{a/L}$ and correspond to a heavily populated medium.

As already mentioned, a point light source, as well as parallel light, are physical fictional entities. Usually light bulbs or high-pressure burners with xenon or mercury arcs are used and can be summarized as point sources. For higher energy efficiency, fluorescence light tubes are used which comprise an area greater than a point source. In the simulation, the model is turned in increments of 7.5 degrees for a total angle of 30 degrees and light intensities are averaged (c.f. Fig.5).

Figure 5 shows light intensities within a culture vessel with $10 \mathrm{mg} \mathrm{Chl} \mathrm{a/L} \mathrm{and} \mathrm{an}$ evenly distributed light from the front with an opening angle of 60 degrees. 


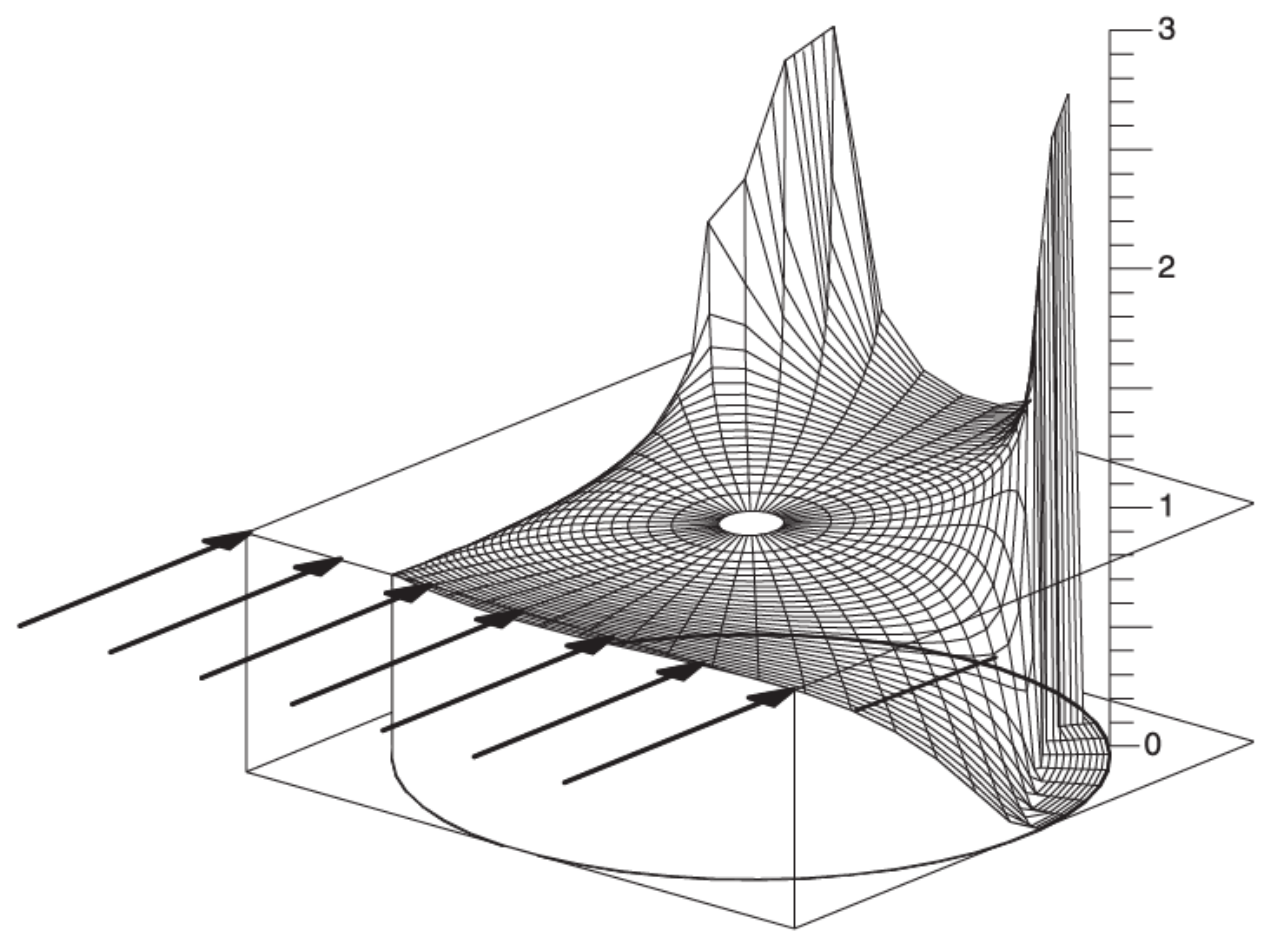

Figure 4. Light intensities, ditto as Fig. 3, but with algae

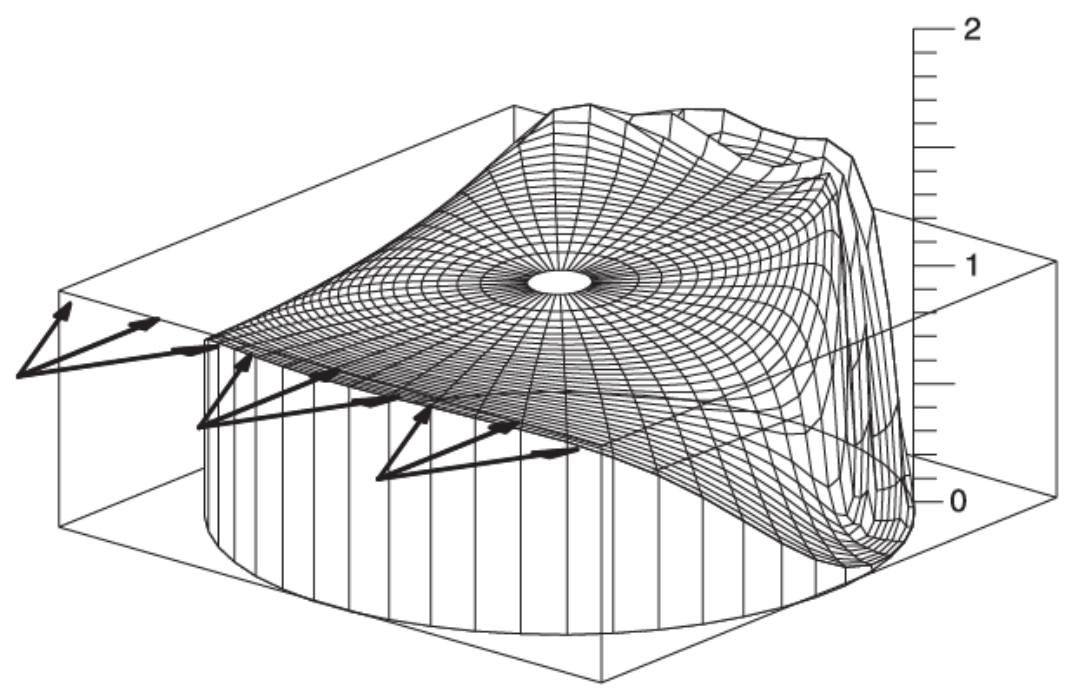

Figure 5. Fluorescence light perpendicular to vessel axis 
In Fig. 5 shading is still noticed perpendicular to the lighting axis, but the high values are avoided. An even better picture can been achieved by using fluorescence tubes at the front and back of the culture, or packing the tubes parallel around the culture tube (\#16 Table 1) (set-up of Meffert 1971).

The basic cause of the problem of uneven light is the form of the vessel, as well as the difference of refractive index of air and glass. If the vessel is standing submerged in water within a right-angled basin most of the differences disappear.

Figure 6 shows the light intensities when the same vessel is immersed in a water bath with a rectangular shape. Whereas there is some reflection of the basin walls, the only remaining optical effect is caused by the glass walls of the vessel and no longer by the form of the culture fluid. Consequently, the shaded areas are almost completely avoided.

Most technicians do not like this set-up because the water bath must be kept clean; and is achieved either by daily water renewal and intensive cleaning or by poisoning.

In Table 1, a summary of light intensities is shown. An algal concentration of $10 \mathrm{mg}$ chlorophyll per liter was chosen for creating a more or less even distribution of light in examples 1-4 where the light is heavily focused. In reality, this concentration rarely occurs but the curves are somewhere closer to cases $0,4,9,12$. The maxima of the distributions are not shown because these values reflect the artifacts created by the pattern of chosen intensity points and could reach very high values relative to the actual geometry of the light source. If shaded areas should be avoid-

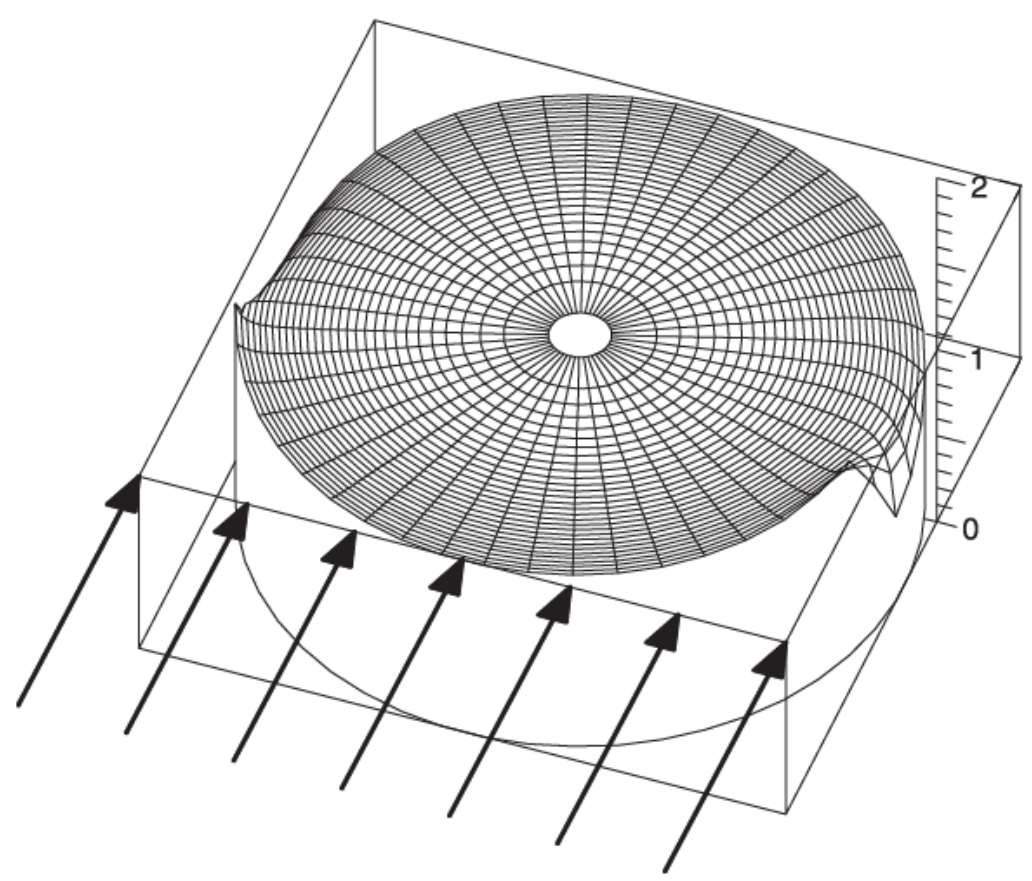

Figure 6. Light within immersed culture vessel illuminated with a point source without algae 

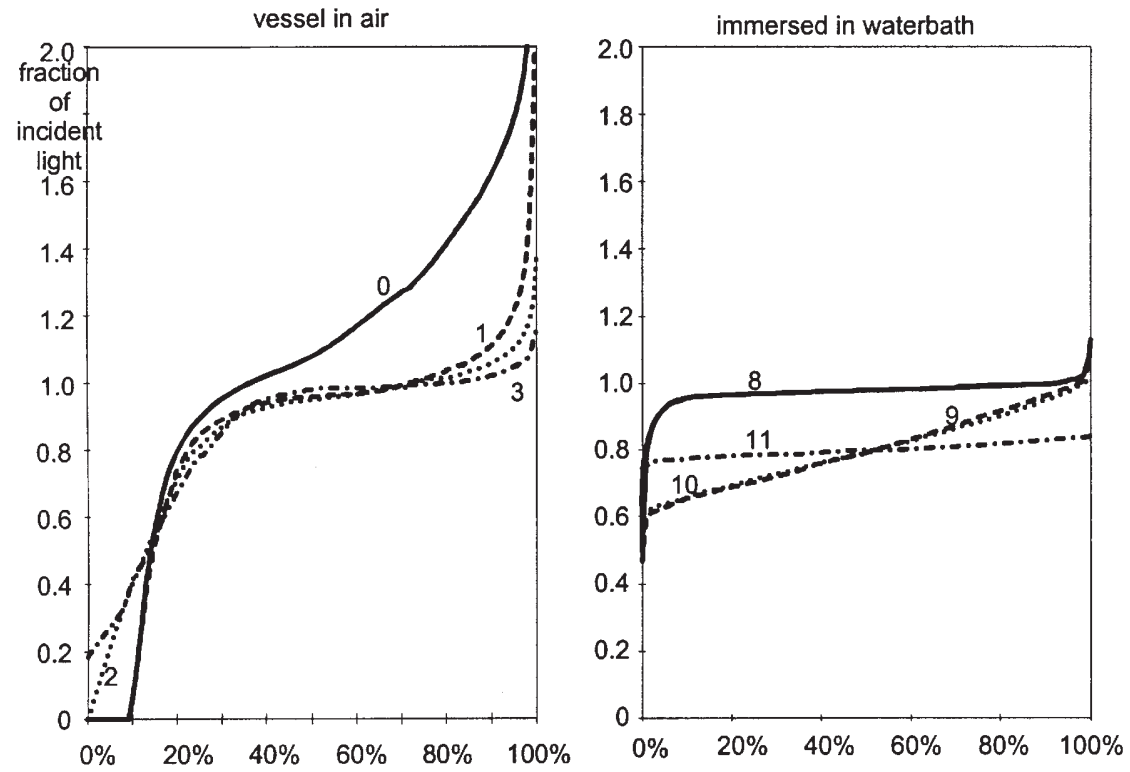

Figure 7a. Frequency distribution of light within a culture vessel, parallel light; Left side: surrounded by air, right side: immersed in a water bath
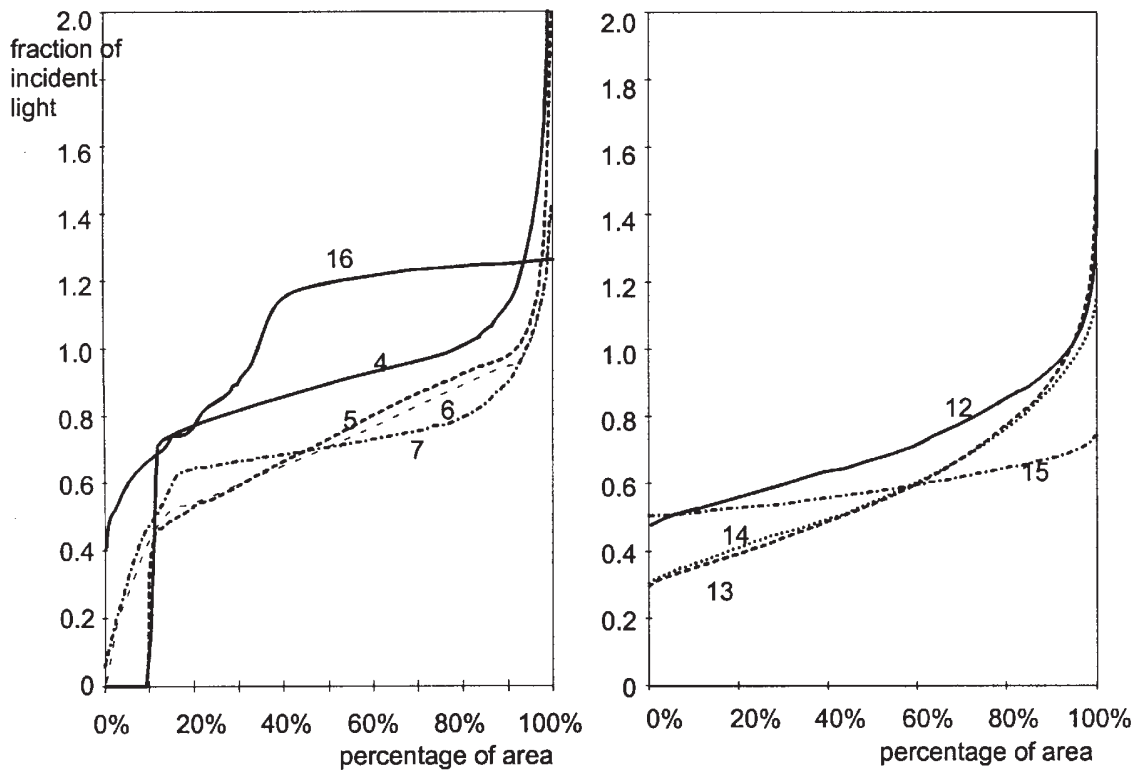

Figure 7b. Frequency distribution of light within a culture vessel, light source at a distance of $23.2 \mathrm{~cm}$. Left side: surrounded by air, right side: immersed in water 


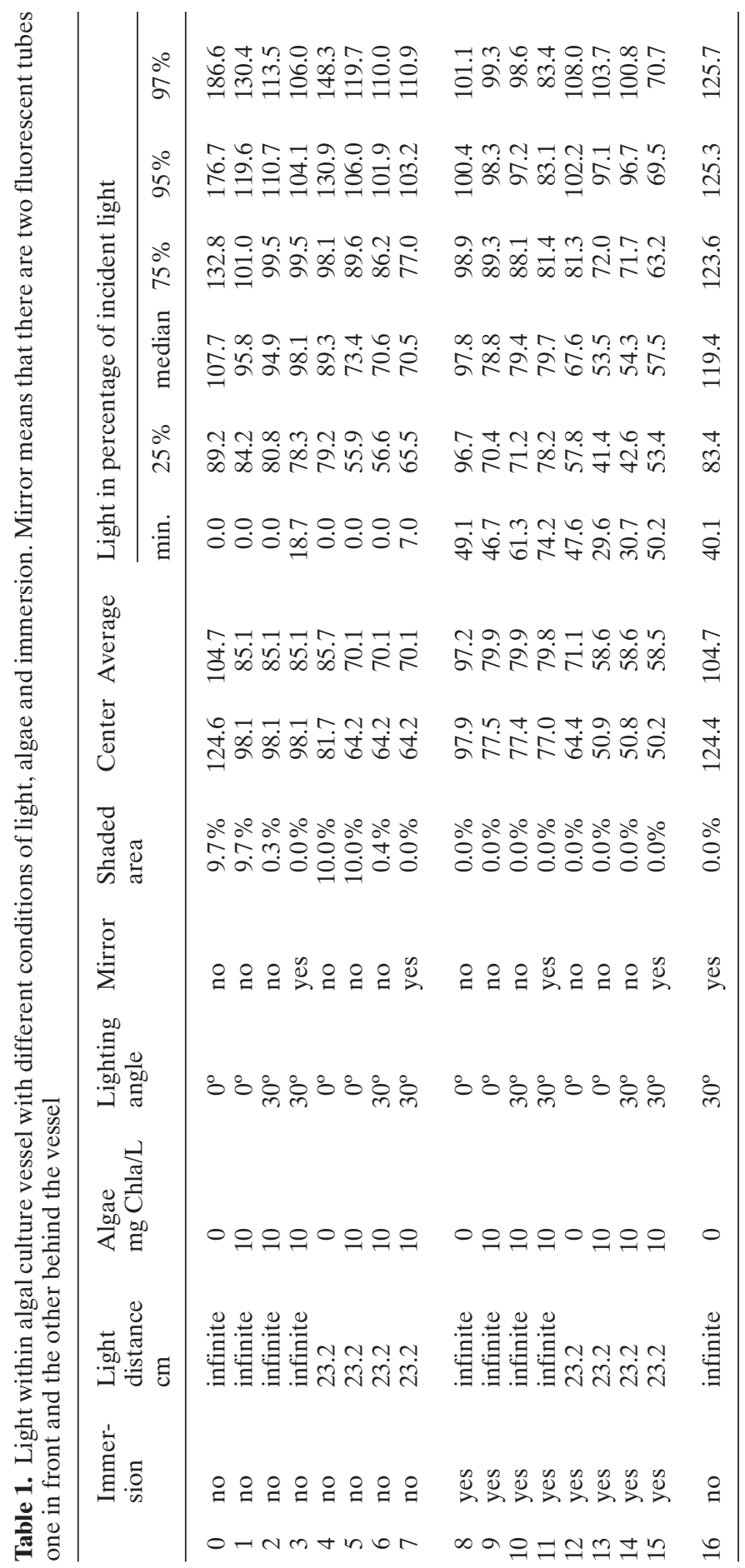


ed, the appropriate lighting is completed via immersion. Even a highly symmetrical design, e.g. \# 16 with 6 fluorescence tubes running parallel to and surrounding the vessel (Meffert, 1971), gives a rather uneven distribution.

Other types of lighting can be through the bottom of the flasks but they usually are poor optical lenses. This large effect is apparent even with visual inspection (the visual perception works on a logarithmic scale (Fechner's ${ }^{4}$ Law, 1860)). Lighting from above is even worse because of the shading by stoppers. A shaker creates surface waves that work as lenses.

\section{Conclusion}

For studying algal responses under steady light conditions, culture devices must be immersed in water to minimize focusing effects. Otherwise, in the worst case, there are orders of magnitude differences in light intensity. The mixing of the culture transports algae through the focusing line and back into the shade, thus simulating the transport of algae from the surface of a lake down to the compensation depth within milliseconds.

At the very least, if one still hesitates to use a water bath, then you cannot report that the algae were cultivated under steady light conditions. Algae react to the amount of light they actually receive.

\section{ACKNOWLEDGEMENTS}

As I publish only when teased, I have to thank my young colleagues for their set-ups of algal cultures, which made a revival of my work necessary. Their new invention of lighting through the bottom or from the top are even worse than our old design. It's not reproducible. As most of the scientific knowledge for the present work is available since Freshnel, I had some trouble in tracing the roots (and citing some literature). The actual foundation was laid by the old Greeks (e.g. Archimedes 287-212 B.C.) and was finished by the Arabs in the first millennium. But nevertheless, it is still an actual problem if "hydroponicists" forget the basics, although the realization needs at least a personal computer because of the reversed algorithms and massive calculations.

\section{REFERENCES}

Fresnel's laws in: CRC Handbook of chemistry and physics: a ready-reference book of chemical and physical data/publ. by the Chemical Rubber Co. Cleveland, Ohio: CRC, 2 ed. 79, 19981999.

GAP (1998): Working Group of SIL on Aquatic Primary Productivity (GAP). Dublin, August 13, 1998.

Garcia-Camacho, F., A. Contreras-Gomez, F.G. Acien-Fernandez, J. Fernandez-Sevilla and E. Molina-Grima, 1999. Use of concentric-tube airlift photobioreactors for microalgal outdoor mass cultures; Enzyme-Microb.Technol. 24: 3-4, pp. 164-172.

Gavrieli, J., 1984. Studies on the autoecology of the freshwater algae flagellate Rhodomonas lacustris Pascher et Ruttner. Diss. ETHZ, Nr. 7595, 77 pg.

Gerthsen, C. and H. Vogel, 1993. Physik, ein Lehrbuch zum Gebrauch neben Vorlesungen 17. ed. Berlin (etc.): Springer 943 pg. ISBN 3-540-56638-4

\footnotetext{
${ }^{4}$ Gustav Theodor Fechner (1801-1887).
} 
Grima, E.M., F.G.A. Fernandez, F.G. Camacho and Y. Chisti, 1999. Photobioreactors: light regime, mass transfer, and scaleup. Journal of Biotechnology. 1999; 70: 1-3, pp. 231-247.

Hirsbrunner, M., 1971. Vergleichende Untersuchungen über Standard-Bioassay-Verfahren (Algentests) und in-situ Experimente. Dipl. ETHZ (EAWAG), 87 pg.

Lambert-Beer law in: Gerthsen (1993)

Marquez, F.-J., K. Sasaki, N. Nishio and S. Nagai, 1995. Inhibitory effect of oxygen accumulation on the growth of Spirulina platensis. Biotechnology Letters 17: 2, pp. 225-228.

Meffert, M.-E., 1971. Cultivation and growth of two planctonic Oscillatoria species. SIL. Mitt. 19, pp. 189-205

Soeder, C. and H. Mohn, 1975. Technologische Aspekte der Mikroalgenkultur. Ges. f. Biotechn Forschg. D. Ges. Hygiene und Mikrobiol. 1. Symp Mikrobielle Proteingewinnung. (Amb. Sep. S 155)

Stefan-Bolzmann law in: Gerthsen (1993)

Tadros, M.G., W. Smith, B. Joseph and J. Phillips, 1993. Yield and quality of cyanobacteria: Spirulina maxima in continuous culture in response to light intensity; Appl. Biochem. Biotechnol. 1993; 39-40, pp. 337-347.

Uehlinger U.F., 1980. Untersuchungen zur Autökologie der planktischen Blaualge Aphanizomenon flos-aquae. Diss. ETHZ, No. 6723, 124 pg.

Received 20 October 1999;

Revised manuscript accepted 22 January 2000.

\section{Appendix}

The formula for Light versus depth, which was used, Imboden's is (Lambert Beer modif.):

$\mathrm{I}_{\mathrm{z}}=\mathrm{I}_{0} \cdot \mathrm{e}\left(-\mathrm{z}\left(\varepsilon_{\mathrm{W}}+\varepsilon_{\mathrm{A}}^{\prime} \mathrm{A}\right)\right)$, where $\varepsilon_{\mathrm{A}}^{\prime}$ is the specific extinction coefficient of algae, $\varepsilon_{\mathrm{W}}$ stands for the extinction of the nutrient solution, and $\mathrm{z}$ for the penetration depth.

Calculation of light densities was done according to ray optics, with a resolution of $1 \mu \mathrm{m}$.

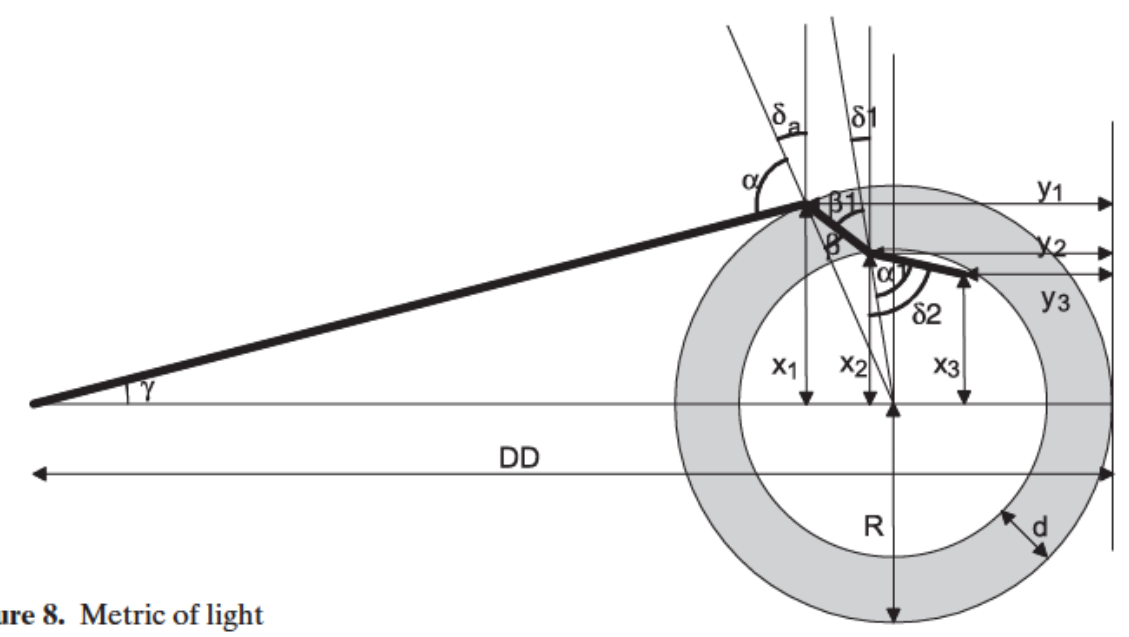

Figure 8. Metric of light 
The origin of co-ordinates is outside, at the back of the vessel:

$\begin{array}{lll}\mathrm{N}_{\mathrm{a}}: & \text { refraction index outside } & {[-]} \\ \mathrm{N}_{\mathrm{w}}: & \text { refraction index wall (glass) } & {[-]} \\ \mathrm{N}_{\mathrm{i}}: & \text { refraction index inside (culture) } & {[-]} \\ \mathrm{r}: & \text { radius of vial } & {[\mathrm{cm}]} \\ \mathrm{D}: & \text { thickness of wall } & {[\mathrm{cm}]} \\ \mathrm{DL}: & \text { distance of light } & {[\mathrm{cm}]} \\ \mathrm{x}_{1}, \mathrm{y}_{1}: & \text { Co-ordinates outer wall } & {[\mathrm{cm}]} \\ \mathrm{x}_{2}, \mathrm{y}_{2}: & \text { Co-ordinates inner wall } & {[\mathrm{cm}]} \\ \mathrm{x}_{3}, \mathrm{y}_{3}: & \text { co-ordinates in vessel } & {[\mathrm{cm}]}\end{array}$

Angles in Radians:

$\gamma: \quad$ lighting angle (Beleuchtungswinkel)

$\alpha: \quad$ entry angle into glass

$\beta$ : $\quad$ leaving angle into glass

$\delta_{\mathrm{a}}: \quad$ right angle to outside wall

$\alpha_{1}$ : leaving out of glass

$\beta_{1}$ : $\quad$ entry out of glass

$\delta_{1}: \quad$ right angle to inner wall

$\delta_{1}$ : $\quad$ lighting angle in vessel

$$
\begin{aligned}
& \mathrm{y}_{1}= \mathrm{r}+\cdot \mathrm{r}^{2}-\mathrm{x}_{1}^{2}, \quad \delta_{\mathrm{a}}=\arctan \left(\mathrm{y}_{1}-\mathrm{r}\right) / \mathrm{x}_{1}, \quad \gamma=\arctan \mathrm{x}_{\mathrm{D}_{\mathrm{L}}-2 \mathrm{r}} \\
& \alpha= \pi / 2-\delta_{\mathrm{a}}+\gamma, \quad \beta=\arcsin \mathrm{N}_{\mathrm{a}} \cdot \sin \alpha \\
& \mathrm{N}_{\mathrm{w}} \\
& \mathrm{CC}= \tan \left(\beta+\delta_{\mathrm{a}}\right)^{2} \mathrm{x}_{1}^{2}+\mathrm{r}^{2}+\mathrm{y}_{1}^{2}+2 \tan \left(\beta+\delta_{\mathrm{a}}\right) \mathrm{x}_{1} \mathrm{r}-2 \tan \left(\beta+\delta_{\mathrm{a}}\right) \mathrm{x}_{1} \mathrm{y}_{1} \\
&-2 \mathrm{ry}_{1}-(\mathrm{r}-\mathrm{D})^{2}
\end{aligned}
$$

Det $=\cdot\left(2 \tan \left(\beta+\delta_{\mathrm{a}}\right)\left(\mathrm{y}_{1}-\tan \left(\beta+\delta_{\mathrm{a}}\right) \mathrm{x}_{1}-\mathrm{r}\right)\right)^{2}-4\left(1+\tan \left(\beta+\delta_{\mathrm{a}}\right)^{2}\right) \mathrm{CC}$

The two solutions of the quadratic equation refer to

$$
\begin{array}{ccc}
\delta_{\mathrm{a}}+\beta>\pi / 2: \quad \mathrm{x}_{2}= & \begin{array}{c}
-2 \tan \left(\beta+\delta_{\mathrm{a}}\right)\left(\mathrm{y}_{1}-\tan \left(\beta+\delta_{\mathrm{a}}\right) \mathrm{x}_{1}-\mathrm{r}\right)-\operatorname{Det} \\
2\left(1+\tan \left(\beta+\delta_{\mathrm{a}}\right)^{2}\right)
\end{array} \\
\delta_{\mathrm{a}}+\beta \quad \pi / 2: \quad \mathrm{x}_{2}=\frac{-2 \tan \left(\beta+\delta_{\mathrm{a}}\right)\left(\mathrm{y}_{1}-\tan \left(\beta+\delta_{\mathrm{a}}\right) \mathrm{x}_{1}-\mathrm{r}\right)+\operatorname{Det}}{2\left(1+\tan \left(\beta+\delta_{\mathrm{a}}\right)^{2}\right)}
\end{array}
$$

where $\mathrm{x}_{2}>\cdot(\mathrm{r}-\mathrm{D})^{2}-\left(\mathrm{y}_{3}-\mathrm{r}\right)^{2}$ would be within the wall, or outside 
and

$$
\begin{aligned}
& \mathrm{y}_{2}>\mathrm{y}_{1}: \quad \mathrm{y}_{2}=\mathrm{r}-\bullet(\mathrm{r}-\mathrm{D})^{2}-\mathrm{x}_{2}^{2} \\
& \mathrm{y}_{1}>\mathrm{y}_{2}: \quad \mathrm{y}_{2}=\mathrm{r}+\bullet(\mathrm{r}-\mathrm{D})^{2}-\mathrm{x}_{2}^{2} \\
& \delta_{1}=\arctan \frac{\mathrm{y}_{2}-\mathrm{r}}{\mathrm{x}_{2}}, \quad \beta_{1}=\beta+\delta_{\mathrm{a}}-\delta_{1}, \quad \alpha_{1}=\arcsin \stackrel{\mathrm{N}_{\mathrm{w}} \sin \beta_{1}}{\mathrm{~N}_{\mathrm{i}}} \\
& \delta_{2}=\delta_{1}+\alpha_{1}, \quad \mathrm{x}_{3}=\frac{\mathrm{y}_{3}-\mathrm{y}_{2}}{\tan \delta_{2}}=\mathrm{x}_{2}
\end{aligned}
$$

Fresnel reflections:

$$
\begin{aligned}
& \mathrm{f}_{1}=\left[1-\left(\begin{array}{c}
\sin \alpha-\beta \\
\sin \alpha+\beta
\end{array}\right)^{2}\right] \times\left[1-\left(\begin{array}{c}
\sin \beta_{1}-\alpha_{1} \\
\sin \beta_{1}+\alpha_{1}
\end{array}\right)^{2}\right] \\
& \mathrm{f}_{2}=\left[1-\left(\begin{array}{c}
\sin \alpha-\beta \\
\tan \alpha+\beta
\end{array}\right)^{2}\right] \times\left[1-\left(\begin{array}{c}
\sin \beta_{1}-\alpha_{1} \\
\tan \beta_{1}+\alpha_{1}
\end{array}\right)^{2}\right] \\
& \text { path }=\cdot\left(\mathrm{x}_{3}-\mathrm{x}_{2}\right)^{2}+\left(\mathrm{y}_{3}-\mathrm{y}_{2}\right)^{2} \\
& \text { local intensity }=\frac{\mathrm{f}_{1}+\mathrm{f}_{2}}{2} \mathrm{e}^{-\operatorname{path}\left(\varepsilon_{\mathrm{w}}+\varepsilon_{\mathrm{A}} \mathrm{Alg}\right)}
\end{aligned}
$$

The calculation started selecting the point $\mathrm{x}_{3}, \mathrm{y}_{3}$ within the vessel and was working backward with the regula falsi to meet $\mathrm{x}_{1}, \mathrm{y}_{1}$. 